\title{
La flexibilización del mercado laboral en Indonesia
}

DOI: 10.32870/mycp.v10i29.306

Cecilia Escobedo Torres*

\section{Introducción}

$\mathrm{E}$ l objetivo de este artículo es ofrecer una aproximación sobre la flexibilización del mercado laboral de Indonesia. La idea es reflexionar sobre el estado actual y los cambios que ha presentado el mercado de trabajo de Indonesia por lo menos en los últimos diez años. Si bien son varios los indicadores que nos permiten dar cuenta del estado del contexto laboral, en este caso sólo se tomará en cuenta la relación entre población económicamente activa, desempleo, subempleo y empleo formal.

Debido a la magnitud de su población, esta economía ocupa el cuarto lugar en el mundo: suma 230 millones de habitantes, de los cuales la mitad se concentra en la isla de Java y el resto se dispersa en un extenso archipiélago. Hasta 1998 la fuerza de trabajo de Indonesia se constituía de 90 millones de personas, la cual se ocupó principalmente en actividades agrícolas y de pesca (55\%), 21 por ciento en la industria y el 29 por ciento restante en servicios (Santa, 1998: 3). Para 2005, Indonesia cuenta ya con las mayores reservas de fuerza de trabajo en la zona, con un total de 105.8 millones de personas en posibilidad de trabajar, de los cuales 94 millones se

* Profesora-Investigadora del Departamento de Estudios del Pacífico de la Universidad de Guadalajara. registraron en las filas del empleo y 10.854 millones en el desempleo.

Los efectos combinados de una creciente urbanización que desplaza a la población agrícola y de la expansión de oportunidades laborales en países vecinos han impulsado a millones de indonesios hacia los circuitos internacionales de trabajadores migratorios (Pérez y Sierra, 2005: 7). El problema más serio para la fuerza de trabajo de Indonesia es la migración laboral y se debe, en parte, a dos razones: el elevado nivel de desempleo en su país natal y las escasas oportunidades de ingresos.

\section{Las características del mercado laboral indonés}

Los asuntos afines al desequilibrio del mercado laboral ${ }^{1}$ en esta economía están relacionados con dos contextos: uno la crisis asiática de 1997 y la otra, la salida de Suharto en seguida del cambio de políticas propuestas por el Fondo Monetario Internacional (FMI).

En Indonesia, al final del régimen de Suharto en 1998 se comenzaba a tomar en cuenta los intereses de los trabajadores, pero éstos fueron controlados -al principio, por la inestabilidad política de la crisis económica asiática de 1997-, y con ello las relaciones en el empleo fueron rigurosamente examinadas por un estricto gobierno autoritario, apoyado por la mili- 
cia. El empleo se caracterizó por el trabajo de mala calidad y de escasos ingresos para los trabajadores, además del rechazo de un pago mínimo de salarios que habían propuesto los empleadores. Ante tal situación, el gobierno de Indonesia contempló a una complicada fuerza laboral como necesaria para fines de crecimiento económico (Bamber y Leggett, 2001: 311-312).

A principios de 1998 el escenario productivo de Indonesia no fue nada prometedor, pues el PIB cayó 6.2 por ciento y la disminución en la producción, el desempleo y la inflación golpearon duramente a esta economía. A medida que el desempleo aumentaba drásticamente, el ministro de Trabajo de Indonesia pronosticaba que ese año habría 15.4 millones de desempleados, equivalente a 17 por ciento de una fuerza laboral de 90 millones (Khor, 2007).

Seguido de esta situación y producto de la crisis asiática de 1997, en los últimos quince años Indonesia comenzó una de las más grandes exportaciones de migrantes laborales a otros países del mundo, con un estimado en los últimos quince años Indonesia comenzó una de las más grandes exportaciones de migrantes laborales a otros países del mundo, con un estimado de 2.6 millones de indonesios migraron cada año aumentó de menos de 90,000 a un promedio de 375,000 por año entre 1996 y 2000. En la actualidad, el número es sustancialmente mayor a este último debido al alcance de la migración irregular (Quinn, 2001: 123).

Aunado a lo anterior, las tasas de desempleo aumentaron entre 1998 y 2005 hasta seis puntos porcentuales; además, conforme se incrementó la demanda laboral, la oferta se fue haciendo cada vez más estrecha; debido a que, mientras la fuerza laboral en 1998 sumó un total de 94 millones 735 mil, los puestos laborales sólo se ofertaron en 87 millones 672 mil, lo que da una tasa de desempleo de 5.77 por ciento. Así, sucesivamente se acentuó un aumento constante, para 2005 la tasa de desempleo alcanzó hasta 11.43 por ciento, lo cual se tradujo en una masa de desempleados del 10 millones $854 \mathrm{mil}$ (cuadro 1).

En ese mismo año (1998), la Organización Internacional del Trabajo (OIT) calculó 5.4 millones de trabajadores que fueron desplazados, produc-

to del impacto de la crisis.
El contexto de desempleo arrojó 18 millode 2.6 millones de indonesios. El Ministerio de Migración explica que la migración laboral ha aligerado los altos porcentajes de pérdida de empleos: la cifra asciende a 40 millones de desempleados (Rudnyckyj, 2004: 409).

A medida que el escenario laboral se convertía en un asunto mucho más complicado, este fenómeno se recrudeció, pues el número de indonesios que buscaron trabajo en el extranjero creció rápidamente en los últimos diez años. Las cifras oficiales indican que el número de trabajadores que nes de desempleados, alrededor de $20 \%$ del total de la fuerza laboral. Por su parte, la Agencia de Planeación Nacional de Indonesia estimó para 1999 un porcentaje de 30 por ciento en el desempleo. Además, las estadísticas oficiales revelaron que más de 18 millones de personas trabajaron sin un salario en el año 2000. El empleo en la agricultura se incrementó hasta 13.3 por ciento entre 1997 y 1998. Así, según el encargado de las contrataciones al interior y exterior 


\section{Análisis}

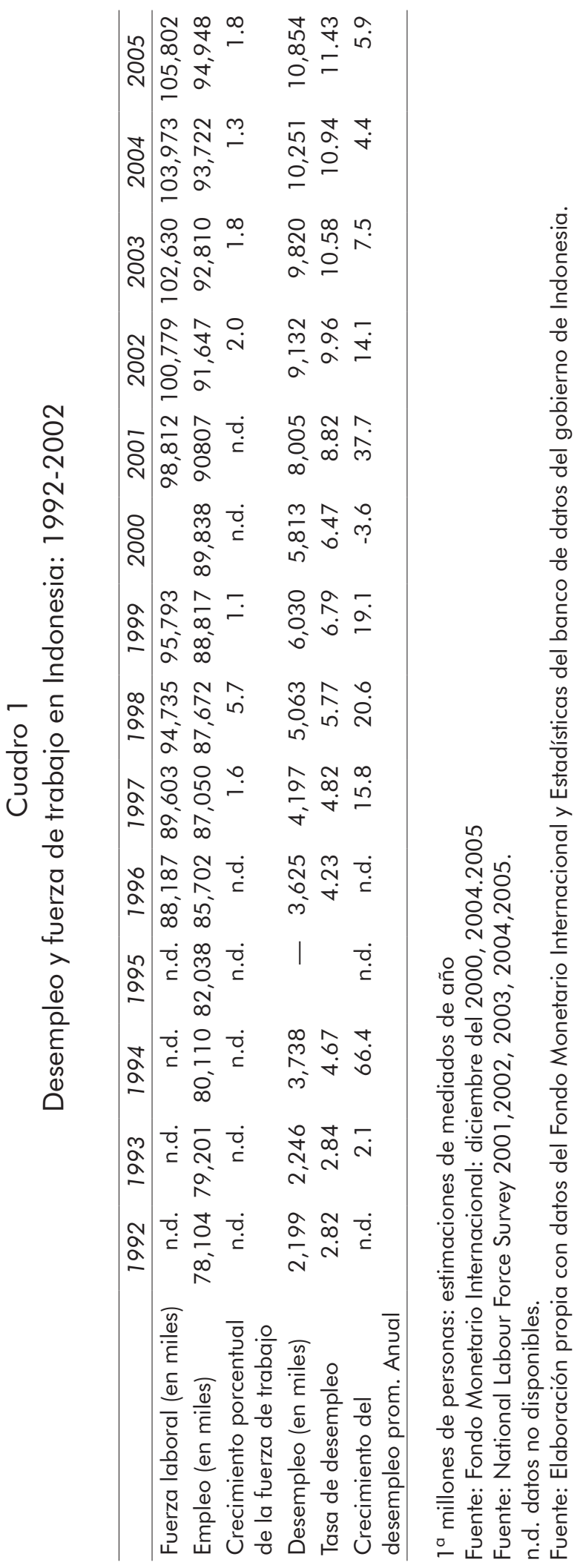


del país, Manpower, para finales del 2001 sumaron 40 millones de desempleados de un total de 90 millones de trabajadores (Kristiansen, 2003: 4-5).

A partir de este último periodo, el escenario laboral en Indonesia ha mostrado una serie de características que denota claramente un desequilibrio casi estructural, donde la fuerza laboral es la que sufre las consecuencias. En términos generales, se observa una tasa de desempleo en aumento constante año con año, así como un promedio totalmente atípico de crecimiento en el desempleo.

\section{La flexibilización del mercado laboral en Indonesia}

Los problemas del desempleo en Indonesia se incrementaron de manera dramática después de la crisis de 1997. Millones de personas buscaron ser contratadas en mercados laborales rurales. Este contexto de desempleo ha generado relaciones sociales indeseables como la criminalidad y conflictos sociales violentos (Kristiansen, 2003: 2). En Indonesia se perdió uno de cada cinco trabajos. El 20\% de la población - casi 40 millones de personas- cayeron bajo la línea de la pobreza. El ingreso nacional de Indonesia bajó 18 por ciento en un año, lo cual significó una de las más grandes caídas de los países en desarrollo (Amjad, 1999: 82).

Según el Ministerio del Trabajo de Indonesia, suman 98.8 millones de trabajadores, de los cuales 60 millones están empleados, 8.1 millones desempleados y 27.7 millones subempleados. Esta última variable incluye entre 65 por ciento o 70 por ciento de la fuerza de trabajo cuyo trabajo se ubica en la economía informal, cifra que contrasta con 55 por ciento en 1996 (Uranga, 2004: 160). Estas cifran dejan entrever que no obstante que en el mercado laboral se genere un tipo de desempleo natural y, por ende, un subempleo producto del aumento de las tasas del despido, la fuerza laboral se encuentra en franca desventaja. En el caso de los trabajadores indonesios, más de un cuarto de la población en edad de trabajar engrosa en ascenso las filas de la informalidad laboral; aunado a esto, el efecto inmediato es la percepción de bajos salarios y escasos derechos laborales.

En el renglón del subempleo, ha aumentado el número de indonesios que se desempeñan fuera de su territorio nacional, en su mayoría bajo condiciones de ilegalidad, en el servicio domestico, en la construcción y en plantaciones. Se calcula que alrededor de cinco millones de personas entran en esta categoría y contribuyen a la economía con aproximadamente 3000 millones de dólares (Uranga, 2004: 160).

La gran mayoría de los contextos laborales del mundo se caracteriza por los abusos de los que son sujetos los migrantes laborales. El caso de los trabajadores indonesios no es la excepción: tan sólo en 1995, éstos percibían 30 centavos de dólar la hora y los australianos 14.40 dólares (Beeson y Hadiz, 1998: 304). Sin embargo, las circunstancias socioeconómicas y políticas por las que atraviesan sus economías de origen los hacen aceptar que, aunque hayan sido sujetos de algún abuso laboral, pueden tener acceso a un empleo; y otros "alaban" los lucrativos salarios a los que tienen acceso, así como los altos estándares de vida de los que se puede gozar bajo estas condiciones.

En términos de desempleo o desocupación, luego de la política de ajuste propuesta por el Fondo Monetario Internacional (FMI) para superar la crisis de la región trajo consigo el descontento popular que llevó al derrocamiento del ex dictador Suharto 
—quien gobernó con mano dura durante 32 años-, y con ello a fines de 1998, el índice de desocupación aumentó hasta pasar de 13 a 20 millones de personas desempleadas (Rojas, 2007).

No obstante los beneficios que se alcanzaron desde la crisis de 1997 a 1998, resta por resolver otros problemas tales como el alto desempleo (abierto y encubierto) que sufren 40 millones de personas (Moncada, 1995: 161). El análisis de las variables que dan cuenta del asunto del desempleo muestra que conforme aumentó la presencia de fuerza laboral, el mercado laboral resolvía de alguna manera la demanda de empleos, puesto que las tasas de desempleo no mostraban variaciones atípicas; un aumento de dos puntos entre 1992 y 1997 señala que se estuvo generando una suerte de desempleo friccional, esto hasta 1997 (cuadro 1).

\section{Conclusiones}

En Indonesia siguen persistiendo problemas de carácter laboral, como en muchas otras economías cuya creciente urbanización desplaza a la población agrícola; cuando las oportunidades de empleo digno se agotan, los trabajadores recurren a escenarios donde la flexibilidad laboral los alinea muchas de las veces en empleos precarios, indignos. En el caso de los indonesios, son sujetos de la expansión de oportunidades laborales en países vecinos y terminan engrosando las estadísticas de trabajadores migratorios. El problema más serio para la fuerza de trabajo de Indonesia es la migración laboral, la cual se debe, en parte, a dos razones: el elevado nivel de desempleo en su país natal y las escasas oportunidades de ingresos.

Bajo el nombre de desarrollo de una mayor "flexibilidad", "responsabilidad" y "competitividad" los gobiernos de las naciones invocan la competencia externa como un imperativo implacable, el cual se convierte en una necesidad y legitima las reformas internas. A final de cuentas, el gobierno se convierte en el albacea de las políticas industriales que no se comprometen con los derechos de los trabajadores.

En resumen, el escenario laboral en Indonesia ha mostrado una serie de características que denotan claramente un desequilibrio casi estructural donde la fuerza laboral es la que sufre las consecuencias. En términos generales se observa una tasa de desempleo en aumento constante año con año, así como un promedio de crecimiento en el desempleo totalmente atípico. my

\section{Notas}

1. El concepto de mercado laboral tiene diferentes explicaciones, entre ellas se puede citar el modelo neoclásico del mercado de trabajo y el desempleo, en el cual el mercado del factor trabajo es considerado en la misma forma que al resto de los mercados de factores, bienes y servicios, donde los salarios son el precio que hay que pagar por los servicios prestados por el factor trabajo. Este modelo tiene como uno de los supuestos el de flexibilidad de los salarios, donde los desplazamientos producidos en función de la oferta y la demanda de trabajo provocarán reajustes salariales; además, la persistencia de un cierto nivel de paro involuntario permanente es explicada mediante dos tipos de razones: el desempleo friccional y el estructural. El desempleo friccional está originado porque muchos de los que acaban de obtener un título profesional no tienen la seguridad de un empleo ni inmediato ni correspondiente con su nivel de estudios, o porque algunos trabajadores deciden dejar su puesto para buscar otro mejor y tardan algún tiempo en encontrarlo. El desempleo estructural se produce por desajustes en la localización y la calificación ofrecida y demandada. Entre otras tesis, este modelo sostiene que es posible que la inversión empresarial se esté 
produciendo en una región determinada mientras que la oferta de trabajo esté en otra. En este proceso, la resistencia de los trabajadores y empresas a trasladarse provocará desempleo. De forma similar, es frecuente que los empleos de nueva creación requieran unas habilidades peculiares de difícil adquisición para el trabajador. $\mathrm{Al}$ acelerarse la velocidad en la innovación tecnológica se amplía la brecha entre las habilidades requeridas y las ofrecidas, por lo que el desempleo estructural aumenta. Incluso en la coyuntura económica más favorable, en las situaciones de pleno empleo, permanecerá siempre un cierto número de trabajadores sin empleo por razones friccionales o estructurales. Es la llamada tasa "normal" o inevitable. Esa tasa varía según los países y las épocas (Martínez, 2004). Existen otras definiciones donde el mercado de trabajo suele estar influido y regulado por el Estado a través del derecho laboral y por una modalidad especial de contratos, los convenios colectivos de trabajo. En la práctica, el mercado de trabajo tiene dos grandes conformaciones relacionadas: una es individual y suele manifestarse mediante la solicitud pública (oferta) de trabajadores por parte de una empresa; la otra es la conformación colectiva, en la que uno o más sindicatos negocia con una empresa, un grupo de empresas, o una organización de empleadores, las condiciones de contratación laboral, estableciendo los acuerdos en un convenio colectivo de trabajo. Para que exista mercado de trabajo es requisito indispensable que el trabajador sea libre, de lo contrario lo que se presenta es en realidad una relación de esclavitud cuyo intercambio se produce en un mercado de personas. A tal efecto, la libertad sindical ha sido considerada un componente indispensable de la libertad de trabajo (Robles, 2001).

\section{Bibliografía}

Amjad, Rashid, Empleabilidad y mundialización: papel fundamental de la formación, boletín Cinterfor, núm. 145, enero-abril, 1999, en: www.cinterfor. org.uy/public/spanish/region/ampro/cinterfor/ publ/boletin/145/pdf/bol6.pdf.

Bamber y Leggett, "Changing employment relations in the Asia-Pacific region", International Journal of Manpower, 2001, p. 4, ABI/FORM global.

Beeson, Mark y Vedi Hadiz, "Labour and the politics of structural adjustment in Australia and Indonesia", Journal of Contemporary Asia, vol. 3, núm. 28, Academic Research Library, 1998, pp. 291-309.

Khor, Martín, "La crisis asiática se convierte en recesión", en: http://www.tercermundoeconomico. org.uy/TME-111/tendencias01.htm, 1999.

Kristiansen, Stein, "Linkages and Rural Non-Farm employment creation: Changing challenges and policies in Indonesia", ESA Working Paper, núm. 03-22, diciembre, 2003. En: http://www.fao.org/ docrep/007/ae055e/aeo55e00.htm.

Martínez Coll, Juan Carlos, "El desempleo", La economía de mercado, virtudes e inconvenientes. En: http://www.eumed.net/cursecon/14/modelo_neoclasico_del_desempleo.htm, 2001.

Moncada García, Dulce Ma., "Indonesia", Revista Asía Pacífico 2005, El Colegio de México, 2005, pp.151-167.

Pérez, Alfredo e lván Roberto Sierra Medel, "¿ Hacia un mercado laboral integrado en el sudeste asiático?", en: http://polcul.xoc.uam.mx/pyc23/08perez.pdf.

Quiin, "Los sueños se convierten en pesadillas para los trabajadores migrantes de Indonesia". En: http:// www.ilo.org/public/spanish/dialogue/octrav/ publ/129/20.pdf., 2001.

Robles, Alberto, "Mercado de trabajo. Instituto del Mundo de Trabajo". En: http://es.wikipedia.org/ wiki/Mercado_de_trabajo, 2001.

Rojas, Miguel, "Las lecciones revolucionarias de Indonesia y el potencial revolucionario de la clase obrera". En: http://www.geocites.com/orcuarta/ lo/loindonesia.htm, 1997.

Rudnyckyi, Daromir, "Technologies or servitude: Governmentality and Indonesian Transnational Labor Migration", Anthropological Quarterly, vol. 77, núm. 3, verano, 2004, pp. 34-407.

Santa Cruz, Arturo, "Indonesia żal borde del abismo?", México y la Cuenca del Pacífico, vol. 1, núm. 2, 1998.

Sotelo Valencia, Adrián, "La gestión del trabajo flexible en la mundialización del capital", Revista Aportes, año VII, núm. 21 , BUAP, México, 2002.

Uranga, Gabriela, "Indonesia", Revista Asia Pacífico 2004, El Colegio de México, 2004, pp. 153162.
MÉXICO YLACUENCADEL PACÍFICO

vol. 10, núm. 29 / mayo - agosto de 2007 